\title{
The Lifelines Cohort Study: a data source available for studying informal caregivers' experiences and the outcomes of informal caregiving
}

M. Oldenkamp ${ }^{1,5^{*}}$, M. Hagedoorn ${ }^{2}$, R. P. Stolk ${ }^{1}$, R. P. M. Wittek ${ }^{3}$ and N. Smidt ${ }^{4}$

\begin{abstract}
Background: Informal care is taking an increasingly important role in our health care system, and an improvement in our understanding of caregiving experiences and outcomes has become more relevant. The Lifelines informal care add-on study (Lifelines ICAS) was initiated within the Lifelines Cohort Study to cover the large heterogeneity in the caregiver population and to investigate the complex interplay among the characteristics of the caregiver, care recipient, and care situation and positive and negative caregiver outcomes. In this paper, we discuss the study design and data collection procedures of Lifelines ICAS, provide a detailed overview of its measures, and describe the caregiver study population.
\end{abstract}

Methods: Lifelines participants who participated in the 2nd Lifelines follow-up questionnaire were asked whether they provided informal care. Subsequently, they were invited to participate in Lifelines ICAS. Descriptive statistics were used to describe all informal caregivers in the 2nd Lifelines follow-up questionnaire and to describe the subsample of informal caregivers participating in Lifelines ICAS.

Results: A total of 11,651 Lifelines participants were self-identified as an informal caregiver and provided basic information about their care situation. A subsample of 965 informal caregivers participated in Lifelines ICAS and completed a comprehensive questionnaire about their care situation. In this subsample, the average age of caregivers was 53 years (SD 9.8), 75\% were female, and 56\% cared for a parent (in-law). Care recipients were on average 68 years old (SD 23.5), and 64\% were female.

Discussion: Considering that informal caregivers are a huge resource for our health care system, Lifelines ICAS enables the study of differences among caregivers, care recipients, and care situations, as well as the study of common characteristics and features across caregiver groups. Notably, data from the Lifelines Cohort Study and Lifelines ICAS are available to all researchers on a fee-for-service basis, and Lifelines ICAS data may be enhanced by one or more follow-up measurements or linkages with other data sources.

Keywords: Informal care, Caregiving experiences, Study design, Add-on study, The Netherlands

\footnotetext{
* Correspondence: m.oldenkamp@umcg.nl

'Department of Epidemiology, University of Groningen, University Medical Center Groningen, PO Box 30.001, 9700 RB Groningen, The Netherlands

${ }^{5}$ The Netherlands Institute for Health Services Research (NIVEL), PO Box 1568,

3500 BN Utrecht, The Netherlands

Full list of author information is available at the end of the article
} 


\section{Background}

Informal caregivers play an increasingly important role in the health care systems of Western societies [1]. The prevalence of informal caregivers in OECD countries (Organisation for Economic Co-operation and Development) ranges from 8 to $16 \%$ and from 18 to $44 \%$, depending on the definition of informal care that is used [1]. In the Netherlands, in 2014, 3.8 million people aged 19 years and older (29\% of the Dutch adult population) provided intensive $(>8 \mathrm{~h}$ a week) or long-term ( $>3$ months) informal care for a relative, such as a spouse, parent (in-law), child, friend, or neighbour [2]. To obtain the benefits of informal care, such as delayed institutionalization of the care recipient [3], caregiving research that aims to improve our understanding of caregiving experiences and the outcomes of informal caregiving has become more relevant [1].

Caregiving research can be characterized by a focus on the complex interplay among the characteristics of the caregivers (e.g., health, other responsibilities besides informal care, educational level, gender), care recipients (e.g., health problems, living situation), and the care situation (e.g., caregiving intensity, type of care relationship, availability of support) and negative (e.g., burden, stress) and positive (e.g., increased self-esteem, satisfaction from caregiving) caregiving outcomes. Compared to noncaregivers, informal caregivers often experience higher levels of stress and depression and lower levels of subjective well-being and physical health [4]. Within the caregiving population, there is considerable variation in how caregivers experience their role and how it affects their health. For example, spousal caregivers experience more burden than adult-child caregivers $[5,6]$, and dementia caregivers experience more burden than caregivers of care recipients without dementia [7, 8]. As there can be large differences among informal caregivers, caregiving studies often focus on homogeneous diagnostic groups of care recipients (e.g., Alzheimer's disease, stroke, cancer) [9] and recruit informal caregivers via these selective groups of care recipients [10]. As a result, informal caregivers in these studies may experience relatively high levels of burden and low levels of positive experiences [11]. In addition, although these studies provide relevant and useful information for specific groups of informal caregivers and their care recipients, their approach also compromises the generalizability of the findings to the larger caregiving population, limits the identification of common features across caregiving populations, and potentially under- or overestimates the associations between variables $[9,11-14]$.

To cover the large heterogeneity in the caregiving population, we conducted an informal care add-on study within the Lifelines Cohort Study: Lifelines ICAS. The Lifelines Cohort Study is a large multi-disciplinary prospective population-based cohort study examining in a unique three-generation design the health and healthrelated behaviours of 167,729 persons living in the north of the Netherlands $[15,16]$. By covering the large heterogeneity and variety in the caregiving population, Lifelines ICAS enables the study of not only differences among but also common features across the wide range of informal caregivers, care recipients, and care situations. As such, it contributes to the further development of caregiving research. Within the Lifelines Cohort Study, an additional informal care questionnaire was distributed among all participants who were identified as informal caregivers and who gave consent to participate in Lifelines ICAS. This paper outlines the study design and data collection procedures, provides an overview of the measurements included in Lifelines ICAS, and describes the caregiver study population.

\section{Methods}

\section{The Lifelines cohort study}

The Lifelines Cohort Study is a large population-based cohort study in the north of the Netherlands that was established to facilitate research on the universal risk factors of multifactorial diseases and their modifiers [15]. The cohort profile of Lifelines has been described elsewhere [16, 17]. Briefly, Lifelines employs a broad range of investigative procedures to assess the biomedical, socio-demographic, behavioural, physical and psychological factors that contribute to the health and disease of the general population, with a special focus on multimorbidity and complex genetics $[15,16]$. The Lifelines Cohort Study was approved by the medical ethical committee of the University Medical Center Groningen, the Netherlands. Participant recruitment and the baseline assessment occurred between 2006 and 2013. All participants signed an informed consent form. For the baseline assessment (over 167,000 participants), participants visited one of the Lifelines research sites to receive a comprehensive physical examination and completed extensive questionnaires at home, including items on health behaviours and health status, medication use, psychosocial factors, and work characteristics. Follow-up is planned for at least 30 years and includes questionnaires administered every 1.5 years, and an updated physical examination every 5 years. Currently, 2 follow-up questionnaires are being carried out, and since January 2014, the participants are invited again for the second physical examination at one of the Lifelines research sites (see Fig. 1). Lifelines is a facility that is open to all researchers. Information on the application and data access procedure is summarized at www.lifelines.net. Detailed information on all collected variables can be found in the online Lifelines Data Catalogue (https://catalogue.lifelines.nl/). 


\begin{tabular}{|c|c|c|c|c|c|c|c|c|}
\hline $2006 \ldots 2010$ & 2011 & 2012 & 2013 & 2014 & 2015 & 2016 & 2017 & $2018 \rightarrow \ldots$ \\
\hline \multicolumn{9}{|c|}{$\begin{array}{l}\text { Baseline Lifelines questionnaire } \\
+1^{\text {st }} \text { visit Lifelines research site }\end{array}$} \\
\hline & \multicolumn{4}{|c|}{$1^{\text {st }}$ Lifelines follow-up questionnaire } & & & & \\
\hline & & \multicolumn{4}{|c|}{$2^{\text {nd }}$ Lifelines follow-up questionnaire } & & & \\
\hline & & & \multicolumn{2}{|c|}{ L Lifelines ICAS* } & & & & \\
\hline & & & & \multicolumn{4}{|c|}{$\begin{array}{l}3^{\text {rd }} \text { Lifelines follow-up questionnaire } \\
+2^{\text {nd }} \text { visit Lifelines research site }\end{array}$} & \\
\hline & & & & & * Lifelines ICAS was distributed between Mav 2013 and July 2014 & $4^{\text {th }}$ Lif & follow-L & stionnaire \\
\hline
\end{tabular}

Fig. 1 Position of Lifelines ICAS within the timeline of the Lifelines Cohort Study

\section{The identification of informal caregivers}

Informal caregivers were identified in the second Lifelines follow-up questionnaire. This questionnaire was distributed among all Lifelines participants aged 18 years and older approximately 5 years after the baseline questionnaire. To identify informal caregivers, we deliberately used a broad definition of informal care and did not place restrictions on the health problems of the care recipient, the type of care relationship, or the caregiving intensity or tasks, except that at least $1 \mathrm{~h}$ of informal care a week had to be provided. Informal care was described to the Lifelines participants as follows: "Unpaid care provided because of chronic disabilities and/or health problems. Informal care concerns care for a loved one, for example, a partner, family member, friend, or other relative. Voluntary work and care for healthy children is not included". Lifelines participants who reported being an informal caregiver answered a few questions about their caregiving situation. Subsequently, they were asked for their consent to participate in Lifelines ICAS. In Table 1, information about informal care that was collected in the second Lifelines follow-up questionnaire is presented, together with some of the other themes that were covered in the second Lifelines follow-up questionnaire.

Based on the baseline and all follow-up questionnaires, a detailed family, health, and employment history can be created. Moreover, additional (longitudinal) research on informal caregiving is possible, and linkages can be made with other data sources, such as health registries and environmental data from Statistics Netherlands.

\section{Lifelines ICAS}

All informal caregivers who consented to participate in Lifelines ICAS between May 2013 and July 2014 received the additional informal care questionnaire (see Fig. 1). We distributed the informal care questionnaire over one full year to exclude seasonal effects. Within a maximum of 2 weeks after the completed second Lifelines follow-up questionnaire was received by Lifelines, the informal care questionnaire was sent by post (paper questionnaire) or email (digital questionnaire), depending on the participant's preference. Participants were requested to complete the questionnaire and return it, using the enclosed reply envelope for the paper questionnaires. No reminders were sent due to logistical and financial reasons. Informal caregivers who cared for more than one care recipient were asked to think about the care recipient to whom they provided most of their informal care when completing the informal care questionnaire.

Lifelines ICAS covered a wide range of themes related to informal caregiving (Table 2), in order to study the many different aspects potentially related to the experiences and outcomes of informal caregiving and the interplay among characteristics of the informal caregiver,

Table 1 Overview of data items about informal care and overview of (some of) the other themes collected in the second Lifelines follow-up questionnaire

Informal care data items in second Lifelines follow-up questionnaire

- Type of care relationship with care recipient (e.g., spouse, parent, child, neighbour; multiple answers possible)

- Intensity of caregiving (hours of household care a week, hours of personal care a week, hours of practical care a week)

- Start date of caregiving (month/year)

- Living together with the care recipient (yes/no)

- Caregiver burden (Self-rated Burden Scale) [22, 23]

- Caregiver satisfaction (modelled after the SRB)

- Consent for participation in informal care add-on study (yes/no)

(Some of the) other themes covered in the second Lifelines follow-up questionnaire

- Psychosocial work environment (Copenhagen Psychosocial Questionnaire) [24, 25]

- Health status (RAND-36 question 1, somatization subscale Symptom Check List) $[26,27]$

- Health care use

- Living and social environment

- Acute stress (List of Threatening Experiences) [28, 29]

- Chronic stress (Long-term Difficulties Inventory) [30]

- Personality (e.g., Goal adjustment scale) [31]

- Lifestyle, including smoking, nutrition (Food frequency questionnaire), and physical activity (SQUASH) $[32,33]$ 
Table 2 Overview of the themes measured in Lifelines ICAS

(a) Caregiving situation: type of care relationship; month and year of start of caregiving; living situation care recipient; participating care recipient in Lifelines.

(b) Health situation care recipient: reasons for care needs (cognitive problems/dementia, psychological problems, physical problems, intellectual problems, behavioural problems); list of (chronic) diseases and disorders [34]; current health situation (temporarily problems, chronical problems, dying)

(c) Health situation of caregiver: health-related quality of life (EQ-5D, EQVAS) [35]

(d) Caregiver activities besides caregiving: paid employment, household tasks, care for children living at home, voluntary work, leisure activities, reduction of activities due to caregiving responsibilities.

(e) Informal care tasks: total hours a week; hours a week per care tasks (household care, personal care, nursing care, emotional support and supervision, assistance with administrative/financial issues, assistance with outside activities)

(f) Support: support focused on caregiver (e.g. social work, caregiver support groups, (un)paid help with own household chores or care for own children, respite care), and support focused on care recipient (e.g. other informal caregiver/volunteer, paid/professional household or personal care, day care/treatment)

(g) Caregiving experiences: Caregiver Reaction Assessment (CRA) [36, 37], Self-rated burden scale (SRB) [22, 23], Positive Aspects of Caregiving scale (PAC) [38], Positive Experiences Scale (PES) [39], Satisfaction with caregiving (VAS scale, modelled after the SRB), relationship quality with care recipient (VAS scale, change since start of caregiving)

(h) Reasons for informal care provision: list of reasons for informal care provision, ranging from 'out of love and affection' and 'satisfaction from caregiving' to 'no availability in care institution' and 'no one else is available'. Four domains can be identified: naturally/obviousness, preference for staying home, no alternatives, and relationships [40]

(i) Informal care and paid work: application of work arrangements, ability to combine informal care and paid work (VAS scale), change in work hours because of caregiving, satisfaction with employer (VAS scale), work arrangements applied by self-employed caregivers

the care recipient, and the care situation and negative and positive caregiving outcomes.

\section{Results}

\section{Informal caregivers in the Lifelines cohort study}

Of the 94,728 Lifelines participants who participated in the second Lifelines follow-up questionnaire, 11,651 (12\%) identified themselves as an informal caregiver (see Fig. 2, upper part). Seventy-five percent were female, their average age was 52 years $( \pm 9.9)$, and most informal caregivers cared for their parent (in-law) (64\% adultchild caregiver). Further characteristics of these informal caregivers and their caregiving situation are presented in the supplementary materials (Additional file 1: Table S1A/B). Figure 3 shows that the percentage of spousal caregivers was the highest in the oldest age categories (61-70 years, $>70$ years), while adult-child caregivers were more often found in the middle age categories (41-50 years, 51-60 years). The percentages of parental caregivers, i.e. those caring for their child (in-law), were relatively stable over the age categories, while other caregivers were found most often in the youngest and oldest age categories $(<31$ years, $>70$ years).

\section{Informal caregivers in Lifelines ICAS}

Of the 11,651 informal caregivers who were identified in the second Lifelines follow-up questionnaire, 7059 (61\%) provided consent to participate in Lifelines ICAS (see Fig. 2, lower part). Of these 7059 informal caregivers who provided consent for participation, 2002 (28\%) consented between May 2013 and July 2014. Subsequently, we distributed the informal care questionnaire among these 2002 informal caregivers. The response rate was $48 \%$, which resulted in 965 informal caregivers who participated in Lifelines ICAS.

Informal caregivers in Lifelines ICAS were on average 53 years of age $( \pm 9.8)$, three-quarters $(75 \%)$ were female, and $56 \%$ were adult-child caregivers. The average age of the care recipients was 68 years $( \pm 23.5)$, and $64 \%$ were female. More information about the informal caregivers in Lifelines ICAS (e.g., socio-demographic characteristics, health-related quality of life), their care recipients (e.g., causes of care need), the care situation (e.g., types and amount of informal care provision, relationship quality, support, caregiving duration), and positive and negative caregiving experiences can be found in the supplementary materials (Additional file 1: Table S2A/B/C, Table S3, Figures S1, S2 and S3).

\section{Discussion}

We conducted an informal care add-on study (Lifelines ICAS) within the Lifelines Cohort Study $[15,16]$, that covered the large heterogeneity in the caregiving population. A substantial proportion of the 965 informal caregivers in Lifelines ICAS were female (75\%), employed (70\%), and adult-child caregivers (56\%), and these characteristics are broadly comparable to those of other caregiving studies [2]. In addition, our caregiver study population contained a wide mixture of informal caregivers, with variation in, for example, types of informal care tasks, intensity of caregiving, care recipient's health problems, and caregiving experiences and outcomes. This wide variation enables the identification of common features across caregiving populations, which is not possible when focusing on specific and more homogeneous groups of informal caregivers $[9,11]$.

By using the second Lifelines follow-up questionnaire to identify informal caregivers in the Lifelines population, we essentially created two caregiver study populations: one large caregiver study population of 11,651 informal caregivers, for whom some basic caregiving information is available, and one smaller caregiver study population of 965 informal caregivers for whom extensive caregiving information is available. Not all informal caregivers in the large study population gave consent to participate in 


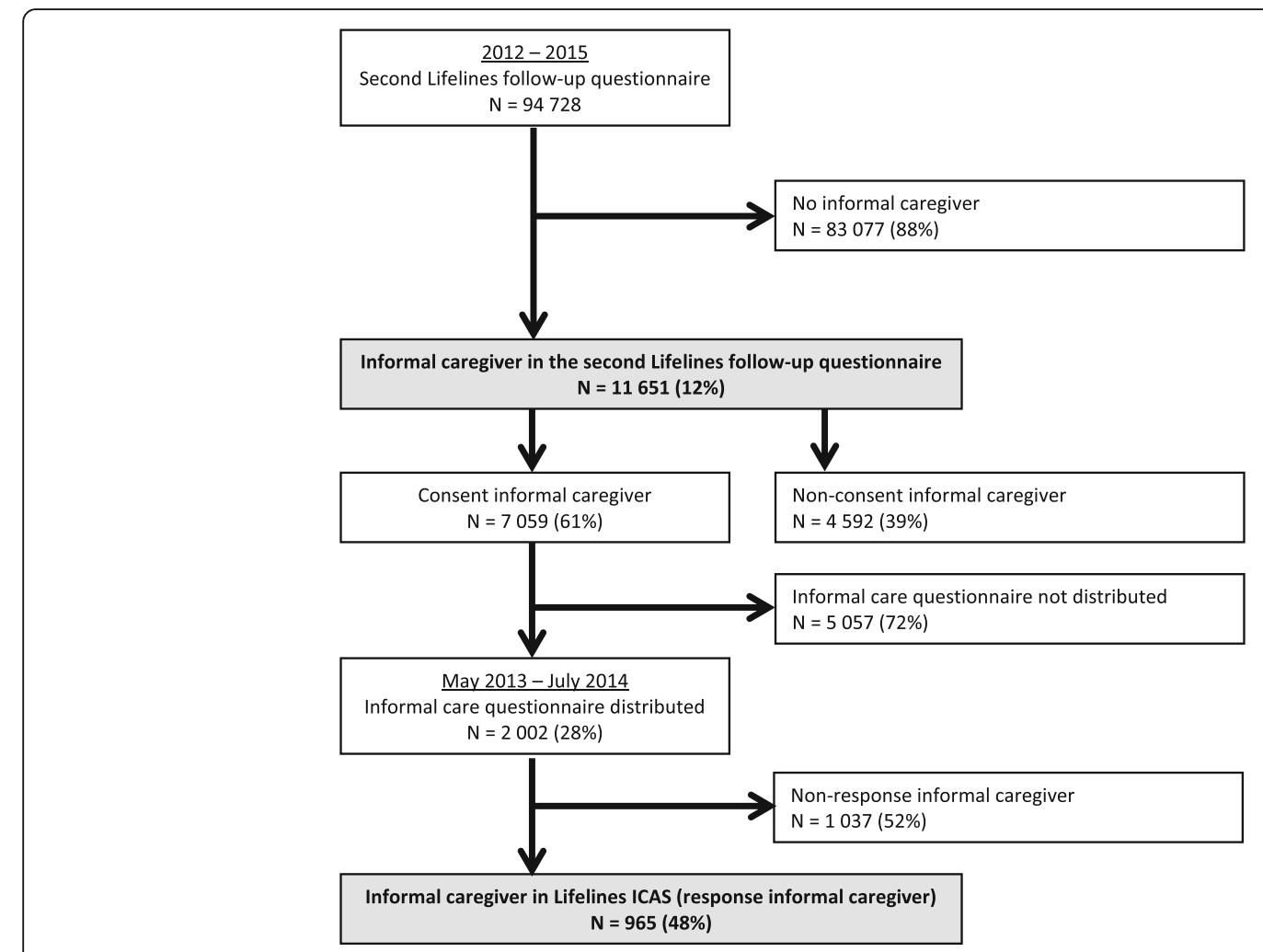

Fig. 2 Flow chart of data collection

Lifelines ICAS (61\% consent rate) or completed and returned the additional informal care questionnaire (48\% response rate). Although informal caregivers with high care demands and high caregiver burden were more likely to consent and respond to Lifelines ICAS, this trend affected only a few associations between caregiver characteristics and caregiver burden (for more information on the nonresponse bias in Lifelines ICAS, see [18]).

Twelve percent of all Lifelines participants indicated that they provided informal care, which is relatively low in comparison to other Dutch caregiver samples $[2,19]$. However, the prevalence of informal care and the composition of the informal caregiver sample depend on the definition of informal care used [20]. We used a broad description of informal care, and included the term 'informal care' in the description. Other studies may have used a more restricted definition of informal care, including, for example, criteria regarding the care recipient's health problems or the type, intensity or duration of informal care provision [20]. Logically, a broad description would result in a higher percentage of informal caregivers. However, it may also be more difficult for people to identify themselves in a broad description, and with a more

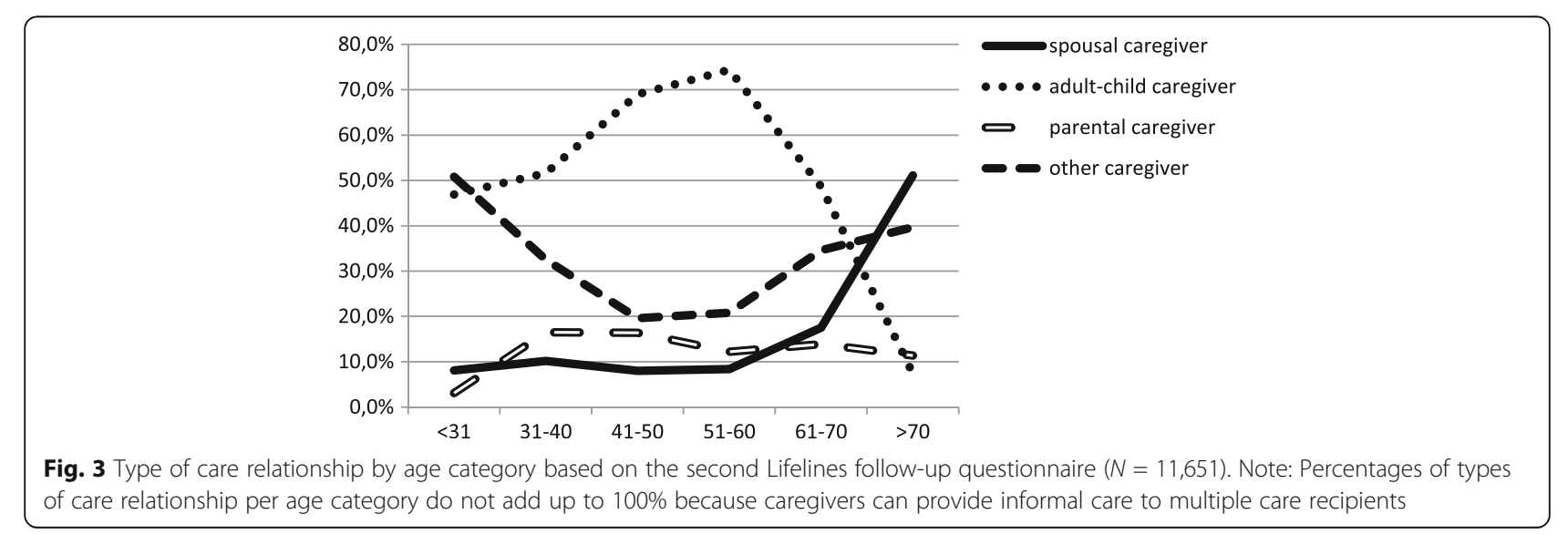


restricted definition, this recognition may be easier. In addition, research has shown that informal caregivers may prefer to think of themselves as relatives or friends of the person with care needs, not as an informal caregiver [21]. As a result, they may not always identify with the term 'informal caregiver' or 'carer' [21]. This consideration is important for future caregiving studies, in which researchers should think carefully about the definition of informal care that they use [20], and researchers may want to consider avoiding the terms 'informal caregiver' or 'carer' when recruiting informal caregivers. The terms used are also important for policy development and the development of support programmes or interventions. People who provide informal care but do not consider themselves to be an informal caregiver may not selfidentify with existing policies or support programmes or interventions in which terms such as informal caregiver are used. Another explanation for the differences in percentages between studies may be the time period that is referenced in the questionnaire. We asked whether Lifelines participants were providing informal care at the time of the questionnaire (point prevalence). This approach results in a lower prevalence of informal care than a question about informal caregiving in the past year [2].

The majority of the 11,651 informal caregivers in the second Lifelines follow-up questionnaire rated their health as good or very good. In addition, the healthrelated quality of life of the 965 informal caregivers in Lifelines ICAS was generally good. This good health may be related to the overrepresentation of middle-aged individuals in the Lifelines Cohort Study, which in turn can be explained by the recruitment strategy used in the Lifelines Cohort Study (index population aged 2549 years) [17]. After adjusting for demographic status, the characteristics of the adult Lifelines participants were broadly representative of the adult population in the north of the Netherlands [17].

\section{Conclusions}

Lifelines ICAS covers a large heterogeneous caregiving population and includes different types of informal caregivers, care recipients, and care situations. This approach enables caregiving researchers to study not only differences but also common characteristics and correlates of outcomes such as caregiver burden and caregiver satisfaction. To conclude, informal caregivers represent a huge resource for society and our health care system, and caregiving research that improves our understanding of caregiving experiences and outcomes is increasingly important and relevant. The data collected in the Lifelines Cohort Study and in Lifelines ICAS may be of great value in this caregiving research and are available to all researchers on a fee-for-service basis. The currently crosssectional Lifelines ICAS may be expanded to obtain one or more follow-up measurements. In addition, a unique feature of Lifelines is that the data can be enriched by linking with other data sources, such as health registries and Statistics Netherlands.

\section{Additional file}

Additional file 1: Electronic supplementary material. (DOCX 696 kb)

\section{Abbreviations}

CRA: Caregiver Reaction Assessment; Lifelines ICAS: Lifelines informal care add-on study; PAC: Positive Aspects of Caregiving scale; PES: Positive Experiences Scale; SRB: Self-rated burden; VAS: Visual analogue scale

\section{Acknowledgements}

The authors wish to acknowledge all participants, and in particular all informal caregivers, in the Lifelines Cohort Study and Lifelines ICAS, the contributing researchers, and everybody involved in the design and implementation of the study.

\section{Availability of data and materials}

Lifelines is a facility that is open to all researchers. Information on the application and data access procedure is summarized at www.lifelines.net.

\section{Funding}

The Lifelines Cohort Study and the generation and management of GWAS genotype data for the Lifelines Cohort Study are supported by the Netherlands Organization of Scientific Research NWO (grant 175.010.2007.006), the Economic Structure Enhancing Fund (FES) of the Dutch government, the Ministry of Economic Affairs, the Ministry of Education, Culture and Science, the Ministry for Health, Welfare and Sports, the Northern Netherlands Collaboration of Provinces (SNN), the Province of Groningen, University Medical Center Groningen, the University of Groningen, Dutch Kidney Foundation and Dutch Diabetes Research Foundation.

The first author was supported by the multidisciplinary research programme Healthy Ageing, Population \& Society (HAPS). HAPS is supported by the University of Groningen. The funding source had no role in the study design, data collection, data analysis, data interpretation, writing of the paper or the decision to submit the paper for publication.

\section{Authors' contributions}

All authors were involved in the design of the study (Lifelines ICAS). The Lifelines Cohort Study collected the data. M. Oldenkamp performed the descriptive analyses and wrote the manuscript. M. Hagedoorn, R.P. Stolk, R. P. M. Wittek, and N. Smidt critically revised the manuscript and approved the final manuscript.

\section{Competing interests}

The authors declare that they have no competing interests.

\section{Consent for publication}

Not applicable.

Ethics approval and consent to participate

Ethical approval for the Lifelines Cohort Study was provided by the medical ethical committee of the University Medical Center Groningen, the Netherlands. Informed consent was obtained from all individual participants included in the study.

\section{Publisher's Note}

Springer Nature remains neutral with regard to jurisdictional claims in published maps and institutional affiliations. 


\section{Author details}

'Department of Epidemiology, University of Groningen, University Medical Center Groningen, PO Box 30.001, 9700 RB Groningen, The Netherlands. ${ }^{2}$ Department of Health Sciences, Health Psychology, University of Groningen, University Medical Center Groningen, PO Box 30.001, 9700 RB Groningen, The Netherlands. ${ }^{3}$ Department of Sociology, University of Groningen, Grote Rozenstraat 31, 9712 TG Groningen, The Netherlands. ${ }^{4}$ Department of Epidemiology, Department of Geriatrics, University of Groningen, University Medical Center Groningen, PO Box 30.001, 9700 RB Groningen, The Netherlands. ${ }^{5}$ The Netherlands Institute for Health Services Research (NIVEL), PO Box 1568, 3500 BN Utrecht, The Netherlands.

Received: 19 December 2016 Accepted: 24 May 2017 Published online: 07 June 2017

\section{References}

1. Colombo F, Llena-Nozal A, Mercier J, et al. Help wanted? Providing and Paying for Long-Term Care. 2011. OECD Health Policy Studies, OECD Publishing; doi:10.1787/9789264097759-en.

2. de Klerk M. Omvang van de informele hulp. (In: de Klerk M, de Boer A Plaisier I, et al., eds. Informele hulp: wie doet er wat? Omvang, aard en kenmerken van mantelzorg en vrijwilligerswerk in de zorg en ondersteuning in 2014). Den Haag: Sociaal en Cultureel Planbureau. 2015:44-64.

3. Luck T, Luppa M, Weber $\mathrm{S}$, et al. Time until institutionalization in incident dementia cases-results of the Leipzig longitudinal study of the aged (LEILA 75+). Neuroepidemiology. 2008;31:100-8. doi:10.1159/000146251.

4. Pinquart $M$, Sörensen S. Differences between caregivers and noncaregivers in psychological health and physical health: a meta-analysis. Psychol Aging. 2003;18:250-67.

5. Pinquart M, Sörensen S. Spouses, adult children, and children-in-law as caregivers of older adults: a meta-analytic comparison. Psychol Aging. 2011;26:1-14. doi:10.1037/a0021863.

6. Broese van Groenou MI, de Boer A, ledema J. Positive and negative evaluation of caregiving among three different types of informal care relationships. Eur J Ageing. 2013;10:301-11. doi:10.1007/s10433-013-0276-6.

7. Schoenmakers B, Buntinx F, Delepeleire J. Factors determining the impact of care-giving on caregivers of elderly patients with dementia. A systematic literature review. Maturitas. 2010;66:191-200. doi:10.1016/j.maturitas.2010.02.009.

8. Vitaliano PP, Zhang J, Scanlan JM. Is Caregiving hazardous to One's physical health? A meta-analysis. Psychol Bull. 2003;129:946-72. doi:10.1037/00332909.129.6.946.

9. Adelman RD, Tmanova LL, Delgado D, et al. Caregiver burden: a clinical review. JAMA. 2014;311:1052. doi:10.1001/jama.2014.304.

10. Verbakel E. Informal caregiving and well-being in Europe: What can ease the negative consequences for caregivers? J EuR Soc Policy. 2014;24:424-41. doi:10.1177/0958928714543902

11. Pruchno RA, Brill JE, Shands Y, et al. Convenience Samples and Caregiving Research: How Generalizable are the Findings? The Gerontologist. 2008;48:820-7.

12. Pinquart $M$, Sörensen $S$. Associations of stressors and uplifts of caregiving with caregiver burden and depressive mood: a meta-analysis. J Gerontol B Psychol Sci soc Sci. 2003;58B:P112-28. doi:10.1093/geronb/58.2.P112.

13. Pinquart $M$, Sörensen S. Gender differences in caregiver stressors, social resources, and health: an updated meta-analysis. J Gerontol B Psychol Sci soc Sci. 2006;61:P33-45. doi:10.1093/geronb/61.1.P33.

14. Kramer BJ. Gain in the Caregiving Experience: Where Are we? What Next? The Gerontologist. 1997;37:218-32. doi:10.1093/geront/37.2.218.

15. Stolk RP, Rosmalen JG, Postma DS, et al. Universal risk factors for multifactorial diseases: LifeLines: a three-generation population-based study. Eur J Epidemiol. 2008:23:67-74. doi:10.1007/s10654-007-9204-4.

16. Scholtens S, Smidt N, Swertz MA, et al. Cohort profile: LifeLines, a three-generation cohort study and biobank. Int J Epidemiol. 2014 doi:10.1093/ije/dyu229.

17. Klijs B, Scholtens S, Mandemakers JJ, et al. Representativeness of the LifeLines Cohort Study. PLoS One. 2015;10:1-12. doi:10.1371/journal. pone.0137203.

18. Oldenkamp M, Wittek RPM, Hagedoorn M, et al. Survey nonresponse among informal caregivers: effects on the presence and magnitude of associations with caregiver burden and satisfaction. BMC Public Health. 2016;16:480. doi:10.1186/s12889-016-2948-6.
19. de Boer A, de Klerk M. Informele zorg in Nederland. Een literatuurstudie naar mantelzorg en vrijwilligerswerk in de zorg. Den Haag: Sociaal en Cultureel Planbureau. 2013;2013:2013-9.

20. de Boer A, de Klerk M, de Wit A, et al. Twee manieren om te vragen of iemand mantelzorg geeft. Tijdschrift Voor Gezondheidswetenschappen. 2016;94:256.

21. Carduff E, Finucane A, Kendall M, et al. Understanding the barriers to identifying carers of people with advanced illness in primary care: triangulating three data sources. BMC Fam Pract. 2014;15:48-57. doi:10. 1186/1471-2296-15-48.

22. van Exel NJ, Brouwer WB, van den Berg B, et al. What really matters: an inquiry into the relative importance of dimensions of informal caregiver burden. Clin Rehabil. 2004;18:683-93. doi:10.1191/0269215504cr743oa.

23. van Exel NJ, Scholte op Reimer WJ, Brouwer WB, et al. Instruments for assessing the burden of informal caregiving for stroke patients in clinical practice: a comparison of CSI, CRA, SCQ and self-rated burden. Clin Rehabil. 2004;18:203-14. doi:10.1191/0269215504cr723oa.

24. Kristensen TS, Hannerz H, Høgh A, et al. The Copenhagen Psychosocial Questionnaire-a tool for the assessment and improvement of the psychosocial work environment. Scand J Work Environ Health. 2005;31:438-49.

25. Pejtersen $\mathrm{JH}$, Kristensen TS, Borg V, et al. The second version of the Copenhagen Psychosocial Questionnaire. Scand J Public Health. 2010; 38:8-24. doi:10.1177/1403494809349858.

26. Hays RD, Morales LS. The RAND-36 measure of health-related quality of life. Ann med. 2001;33:350-7. doi:10.3109/07853890109002089.

27. Derogatis LR, Cleary PA. Confirmation of the dimensional structure of the SCL-90: a study in construct validation. J Clin Psychol. 1977;33:981-9.

28. Brugha TS, Cragg D. The List of Threatening Experiences: the reliability and validity of a brief life events questionnaire. Acta Psychiatr Scand. 1990;82: 77-81. doi:10.1111/j.1600-0447.1990.tb01360.x.

29. Brugha T, Bebbington P, Tennant C, et al. The List of Threatening Experiences: a subset of 12 life event categories with considerable longterm contextual threat. Psychol Med. 1985;15:189-94. doi:10.1017/ S003329170002105X.

30. Hendriks AAJ, Ormel J, van de Willige G. Long-term difficulties measured by a self-report questionnaire and semi-structured interview: a comparison of methods [in Dutch]. Gedrag en Gezondheid. 1990;18:273-83.

31. Wrosch C, Scheier MF, Miller GE, et al. Adaptive self-regulation of unattainable goals: Goal disengagement, Goal reengagement, and subjective well-being. Personal Soc Psychol Bull. 2003;29:1494-508. doi:10. 1177/0146167203256921.

32. Siebelink E, Geelen A, de Vries J. H.M. Self-reported energy intake by FFQ compared with actual energy intake to maintain body weight in 516 adults. Br J Nutr. 2011;106:274-81. doi:10.1017/S0007114511000067.

33. Wendel-Vos G, Schuit AJ, Saris WHM, et al. Reproducibility and relative validity of the short questionnaire to assess health-enhancing physical activity. J Clin Epidemiol. 2003;56:1163-9.

34. Lokale en nationale monitor gezondheid (in Dutch only). 2013. Available at: https://www.monitorgezondheid.nl/home.xml.

35. Brooks R. EuroQol: the current state of play. Health Policy. 1996;37:53-72. doi:10.1016/0168-8510(96)00822-6.

36. Given CW, Given B, Stommel M, et al. The Caregiver Reaction Assessment (CRA) for caregivers to persons with chronic physical and mental impairments. Res Nurs Health. 1992;15:271-83.

37. Nijboer $C$, Triemstra M, Tempelaar $R$, et al. Measuring both negative and positive reactions to giving care to cancer patients: psychometric qualities of the Caregiver Reaction Assessment (CRA). Soc Sci Med. 1999:48:1259-69.

38. Tarlow B, Wisniewski S, Belle S, et al. Positive aspects of caregiving Contributions of the REACH project to the development of new measures for Alzheimer's caregiving. Res Aging. 2004;26:429-53. doi:10.1177/ 0164027504264493.

39. de Boer AH, Oudijk D, Broese van Groenou Ml, et al. Positive experience through informal care: construction of a scale. Tijdschr Gerontol Geriatr. 2012;43:243-54.

40. Timmermans JM. Mantelzorg. Over de hulp van en aan mantelzorgers. Den Haag: Sociaal en Cultureel Planbureau; 2003. p. 1. 